\title{
Stress reactivity links childhood trauma exposure to an admixture of depressive, anxiety, and psychosis symptoms
}

Citation for published version (APA):

van Nierop, M., Lecei, A., Myin-Germeys, I., Collip, D., Viechtbauer, W., Jacobs, N., Derom, C., Thiery, E., van Os, J., \& van Winkel, R. (2018). Stress reactivity links childhood trauma exposure to an admixture of depressive, anxiety, and psychosis symptoms. Psychiatry Research, 260, 451-457.

https://doi.org/10.1016/j.psychres.2017.12.012

Document status and date:

Published: 01/02/2018

DOI:

10.1016/j.psychres.2017.12.012

Document Version:

Publisher's PDF, also known as Version of record

Document license:

Taverne

Please check the document version of this publication:

- A submitted manuscript is the version of the article upon submission and before peer-review. There can be important differences between the submitted version and the official published version of record.

People interested in the research are advised to contact the author for the final version of the publication, or visit the DOI to the publisher's website.

- The final author version and the galley proof are versions of the publication after peer review.

- The final published version features the final layout of the paper including the volume, issue and page numbers.

Link to publication

\footnotetext{
General rights rights.

- You may freely distribute the URL identifying the publication in the public portal. please follow below link for the End User Agreement:

www.umlib.nl/taverne-license

Take down policy

If you believe that this document breaches copyright please contact us at:

repository@maastrichtuniversity.nl

providing details and we will investigate your claim.
}

Copyright and moral rights for the publications made accessible in the public portal are retained by the authors and/or other copyright owners and it is a condition of accessing publications that users recognise and abide by the legal requirements associated with these

- Users may download and print one copy of any publication from the public portal for the purpose of private study or research.

- You may not further distribute the material or use it for any profit-making activity or commercial gain

If the publication is distributed under the terms of Article $25 \mathrm{fa}$ of the Dutch Copyright Act, indicated by the "Taverne" license above, 


\title{
Stress reactivity links childhood trauma exposure to an admixture of depressive, anxiety, and psychosis symptoms
}

\author{
Martine van Nierop ${ }^{\mathrm{a}, *}$, Aleksandra Lecei ${ }^{\mathrm{i}}$, Inez Myin-Germeys ${ }^{\mathrm{a}}$, Dina Collip ${ }^{\mathrm{b}}$, \\ Wolfgang Viechtbauer ${ }^{\mathrm{b}}$, Nele Jacobs ${ }^{\mathrm{b}, \mathrm{c}}$, Catherine Derom ${ }^{\mathrm{d}, \mathrm{e}}$, Evert Thiery ${ }^{\mathrm{f}}$, Jim van Os ${ }^{\mathrm{b}, \mathrm{g}}$, \\ Ruud van Winkel ${ }^{\mathrm{h}, \mathrm{i}}$ \\ a KU Leuven, Department of Neuroscience, Research group Psychiatry, Center for Contextual Psychiatry, Leuven, Belgium \\ ${ }^{\mathrm{b}}$ Maastricht University Medical Center, Dept. of Psychiatry \& Neuropsychology, School for Mental Health \& Neuroscience, Maastricht, The Netherlands \\ ${ }^{\mathrm{c}}$ Faculty of Psychology and Educational Sciences, Open University of the Netherlands, Heerlen, The Netherlands \\ ${ }^{\mathrm{d}}$ Centre of Human Genetics, University Hospital Leuven, Dept. of Human Genetics, Leuven, Belgium \\ e Department of Obstetrics and Gynaecology, Ghent University, Ghent, Belgium \\ ${ }^{\mathrm{f}}$ Dept. of Neurology, Ghent University Hospital, Ghent, Belgium \\ ${ }^{g}$ King's College London, King's Health Partners, Dept. of Psychosis Studies, Institute of Psychiatry, London, United Kingdom \\ ${ }^{\text {h }}$ University Psychiatric Center KU Leuven, Leuvensesteenweg 517, 3070 Kortenberg, Belgium \\ ${ }^{\mathrm{i}}$ KU Leuven, Department of Neuroscience, Research group Psychiatry, Center for Clinical Psychiatry, Belgium
}

\section{A R T I C L E I N F O}

\section{Keywords:}

ESM

General population

Mixed phenotype

Daily life stressors

Psychopathology mechanism

Symptom development

Childhood trauma

\begin{abstract}
A B S T R A C T
Childhood trauma exposure has been associated with a clinically relevant mixed phenotype of psychopathology composed of depressive, anxiety, and psychosis symptoms, across healthy and clinical samples. Altered stressreactivity after exposure to childhood trauma may be a plausible underlying mechanism explaining this association. In a general population sample of female twins ( $\mathrm{T} 0=564$; $\mathrm{T} 1=483$ ), associations between childhood trauma exposure and symptom profile (no symptoms, isolated symptoms, or a mixed phenotype) on the one hand, and daily life stress reactivity on the other were investigated. Daily life stress reactivity was measured using the Experience Sampling Method (ESM), and was defined as negative affect reactivity to minor daily life stressors. Individuals exposed to childhood trauma who reported a mixed phenotype of psychopathology showed a significant increase in emotional reactivity to daily life stress (activity and social stress), compared with trauma-exposed individuals without a mixed phenotype. In the trauma-exposed mixed phenotype group, increased emotional reactivity to event-stress predicted more severe symptoms at \pm 14 month follow-up. This study found evidence that may link heightened emotional reactivity to stress in individuals with a trauma history to the risk for later comorbid psychopathology.
\end{abstract}

\section{Introduction}

Associations between exposure to childhood trauma and psychopathology in adulthood, such as depression (Lindert et al., 2014), anxiety (Lindert et al., 2014), and psychosis (Varese et al., 2012), have been well documented. Rather than increasing the risk for any one category of psychopathology, childhood trauma has been found to be associated with a mixed phenotype of psychopathology, including affective, psychotic, and anxiety symptoms cutting across diagnostic boundaries (Wigman et al., 2012; van Nierop et al., 2015a). Furthermore, it has been found that individuals exposed to childhood trauma who manifest this mixed phenotype of psychopathology show poorer functioning in vocational, social, and clinical domains (van Nierop et al., 2015b). Based on these findings, we proposed that stratifying according to aetiology (trauma exposure) and symptom profile (mixed phenotype) identifies a subgroup of patients that share at least part of a causal pathway, tend to have a worse outcome, and may benefit from additional care (van Nierop et al., 2015b).

Using such a stratification approach has been successfully adopted in somatic medicine, where either environmental stratification (e.g., smoking habits in throat cancer (Petrakos et al., 2012)) or genetic stratification (Bria et al., 2013; Ahmed et al., 2015) has driven treatment choice and prognostic accuracy by uncovering etiological pathways in subgroups identified by their genetic or environmental vulnerability. It has been argued that adopting a stratified approach may also be a fruitful strategy in psychiatry (Kapur et al., 2012; Teicher and

\footnotetext{
* Corresponding author.

E-mail address: martine.vannierop@kuleuven.be (M. van Nierop).
} 
Samson, 2013), and studies using this approach are beginning to provide evidence to support this claim. For example, in studies assessing DNA methylation pattern differences between childhood trauma exposed and non-exposed patients who, e.g. were diagnosed with PTSD or committed suicide, it has been found that stratification according to trauma history may help in uncovering biologically distinct subgroups (McGowan et al., 2009; Mehta et al., 2013). These findings were similar across different patient samples, such as patients with posttraumatic stress disorder (Mehta et al., 2013). This suggests that exposure to trauma early in life may set in motion similar stress-related biological processes, even though the ultimate expression of psychopathology may be phenotypically diverse.

An important aspect is that not all individuals exposed to childhood trauma develop psychopathology, and if they do, not all will display cooccurring affective, psychotic, and anxiety symptoms. If we assume that environmental stratification by childhood trauma identifies a subgroup of individuals with co-occurring symptoms, then these individuals should share at least part of an etiological pathway that is specific for this subgroup. A possible underlying mechanism could be an altered reactivity to stress. Exposure to a severe stressor, such as childhood trauma, may lead to sensitization to future (smaller) stressors, ultimately accumulating into a psychopathological outcome (van Winkel et al., 2008). Previous studies on psychosis liability have demonstrated that a history of trauma in psychosis patients is associated with stronger emotional responses to (small) daily stressors (e.g. Lardinois et al., 2011; Collip et al., 2008). Moreover, alterations of stress sensitivity in traumatized individuals have been hypothesized to underlie a specific subtype of depression that frequently occurs in comorbidity with anxiety disorders (for a review see e.g. Heim and Nemeroff, 2001). It is therefore likely that changes in stress reactivity are not specific for any one disorder, but constitute a general pathway from childhood trauma exposure to a mixed phenotype of psychopathology (van Nierop et al., 2015a, 2015b).

Stress reactivity can be measured at the behavioural level using the Experience Sampling Method (ESM) (Delespaul, 1995; Hektner et al., 2007). ESM is a structured diary technique assessing daily life hassles and mood as they occur in real life. Thus, it allows assessing participants' emotional reactions to daily stressors throughout the day, producing a very fine-grained assessment of stress reactivity. Studies using ESM have consistently reported associations between exposure to childhood trauma and increased emotional reactivity to stress (Glaser et al., 2006; Wichers et al., 2009; Lardinois et al., 2011; Wigman et al., 2013). Moreover, previous studies using ESM to measure stress found evidence that different kinds of stressors, such as event-stress, activitystress and social-stress, are distinct measures (e.g. Myin-Germeys et al., 2001).

The present study aims to assess the hypothesis that individuals exposed to childhood trauma with a mixed phenotype of psychopathology exhibit increased daily life stress reactivity, at the level of subjective experience. In other words, it is hypothesized that a history of trauma increases the risk for psychopathology, and that the amount of daily life stress reactivity moderates this association. By contrasting individuals exposed to trauma, with or without a mixed phenotype, any differences in stress reactivity may be indicative of an etiological pathway, explaining why some, but not all, develop a mixed phenotype after trauma exposure (Fig. 1). Furthermore, by looking at three different kinds of stress-responses separately (event-stress, activity-stress, social-stress), their unique etiologic contribution to psychopathology will be examined.

However, by grouping individuals based on trauma exposure and symptom profile (and thus using a cross-sectional approach), no inferences can be made on the direction of the effects. It is possible that an increase in stress reactivity is not a cause of psychopathology, but rather a temporal state associated with having more severe symptoms. Therefore, we will use longitudinal data, assessing the hypothesis that increases in stress reactivity at baseline are associated with symptom

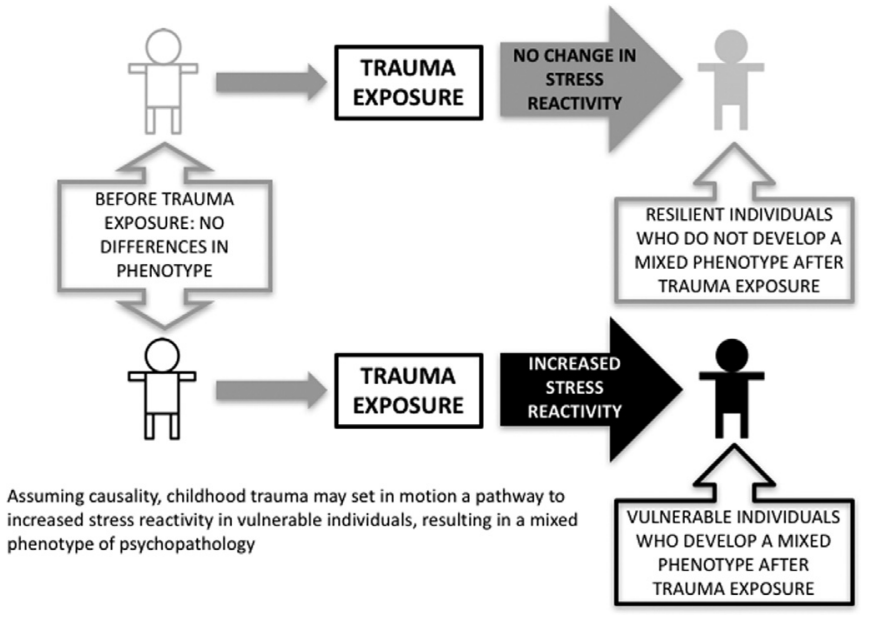

Fig. 1. Etiological pathway of a mixed phenotype of psychopathoiogy.

severity at follow-up.

\section{Methods}

\subsection{Sample}

621 females were recruited from the East Flanders Prospective Twin Survey and from birth registers of Flemish municipalities in Belgium as part of a larger study investigating gene-environment interactions in vulnerability to mental disorders (Derom et al., 2013). The project was approved by the local ethics committee and all participants gave written informed consent. The sample was female only, given evidence for sex-specific differences in response to stress (Pohl et al., 2007; Weekes et al., 2008). The participants were assessed at baseline (T0) at home. Follow-up data (T1) was collected using questionnaires and telephone interviews 4 months later. All interviews were performed by trained research psychologists or graduate psychological assistants.

\subsection{Measures}

\subsubsection{Experience sampling method}

At baseline, data on daily life stress reactivity were measured using the Experience Sampling Method (ESM (Csikszentmihalyi and Larson, 1987; DeVries, 1992; Delespaul, 1995; Myin-Germeys et al., 2009]). ESM is a momentary assessment technique to assess individuals in their daily living environment and has been extensively validated for use in studying the immediate effects of stressors on mood (Myin-Germeys et al., 2001; Myin-Germeys and van Os, 2007). Participants received a digital wristwatch and a set of ESM self-assessment forms collected in a booklet for each day. The wristwatch was programmed to emit a signal (beep) ten times a day at an unpredictable moment in each of ten 90 min time blocks between 7:30 and 22:30 h, on five consecutive days.

After each beep, subjects were asked to fill out the ESM self-assessment forms within $15 \mathrm{~min}$, concerning thoughts, mood, current context (activity, persons present, location), and appraisals of the current situation. Also, participants were asked to report whether they had consumed food, coffee, alcohol, and/or tobacco since the previous beep.

In order to verify whether the subjects had completed the form within $15 \mathrm{~min}$ of the beep, the time at which subjects indicated that they completed the report was compared to the actual time of the beep. All reports completed more than 15 min after the signal were excluded from the analysis as earlier work has shown that after this interval reports are less reliable due to memory distortion, and consequently less valid (Delespaul, 1995). Subjects with less than 17 (out of 50) valid reports were similarly excluded (Delespaul, 1995). 
Consistent with earlier work (Myin-Germeys et al., 2001), event stress was conceptualized as subjective appraised stressfulness of daily life events. After each beep, subjects rated the most important recent event on a 7 -point Likert scale $(-3=$ very unpleasant to $3=$ very pleasant). Only the scores -3 through 0 were used in the present study, thereby only including unpleasant events. These scores were recoded in order for the most unpleasant events to have the highest scores (i.e., 0-3). Activity stress (Myin-Germeys et al., 2001) was measured by asking the participant to appraise what they are doing at the current moment, with three items: 'I am skilled to do this activity' (reverse scored), 'I would rather do something else', and 'This activity requires effort' (all scored on a Likert scale from 1 [not at all] to 7 [very]). The mean of these three items constituted the activity stress score. Social stress was conceptualized by asking the participants whether they are with other people at the moment, and if they are, how pleasant they rate their company (reversed scored), and whether they would rather be alone (Myin-Germeys et al., 2001). Both items were scored on a Likert scale from 1 (not at all) to 7 (very), and the mean of these items constituted the social stress score.

A negative affect (NA) scale was constructed based on six items, comprising the mean scores of the mood items "insecure", "lonely", "anxious", "down", "irritated", and "guilty", each rated on a Likert scale ranging from 1 (not at all) to 7 (very).

\subsubsection{Childhood trauma}

Childhood adversity was assessed at baseline using a self-report questionnaire based on the Dutch translation of the 70-item Childhood Trauma Questionnaire (CTQ (Bernstein et al., 1994)). However, only the items of a more recent and shorter CTQ version (Bernstein et al., 1997) were used, and at the request of the Twin Registry, the most explicit items concerning sexual and physical abuse were omitted. Less explicit items were retained. The questionnaire thus consisted of 21 items reflecting positive events such as a happy childhood/youth, interparental/marital harmony/love, feeling safe and respect of privacy as well as negative events such as physical abuse, emotional neglect, material problems in parental household, and stressful life events. Participants rated the frequency of the experience during childhood and/or adolescence on a scale from 1 (never) to 5 (always). Positive events were recoded to reflect adverse experiences. A continuous variable 'childhood trauma' was constructed based on the mean of all 21 items (possible range 1-5).

\subsubsection{Symptoms}

The Symptom CheckList - 90 - revised (SCL-90 (Derogatis et al., 1976)) used to assess psychopathology at baseline and follow-up. The SCL-90-r is a self-report inventory measuring psychological symptoms and psychological distress. It comprises nine dimensions (somatization, obsessive-compulsive, interpersonal sensitivity, depression, anxiety, hostility, phobic anxiety, paranoid ideation, psychoticism, global severity index, positive symptom distress index, and positive symptom total). Subscales can be used separately or a global severity score can be defined by calculating the mean of all items of the nine subscales. The questionnaire asks the participants to rate to what extent they were bothered by each item in the past week, on a scale of 1 (not at all) to 5 (very much so).

At baseline, the SCL-90-r was used for the assessment of (sub)clinical depression (13 items), anxiety (10 items), and psychosis (10 items psychoticism, 6 items paranoia) at both the baseline and follow-up measurements. For analyses assessing associations between stress reactivity and symptom severity at follow-up, the global severity score of the SCL-90 was used.

\subsubsection{Group}

Participants were stratified by trauma and symptom profiles. Childhood trauma was dichotomized to low and high trauma by the 80th percentile, consistent with previous studies (Heins et al., 2011; van Nierop et al., 2015b). As most participants reported at least one item with a score of one or above on the SCL-90, presence of symptoms was considered for items with scores of 3 and higher, resulting in ratings of 0 (not at all, a bit) and 1 (somewhat, quite a lot, very much so). Absence of a mixed phenotype (MP-) of psychopathology was defined as having no symptoms, or isolated symptoms only (i.e., depression only, anxiety only, or psychosis only). Presence of a mixed phenotype $(\mathrm{MP}+)$ was defined as having any combination of two symptom types, or all three symptoms. A 'group' variable was formed by combining the dichotomous trauma score with the dichotomous MP score, resulting in values 0 (low trauma, absence of mixed phenotype; Trauma-/MP-), 1 (low trauma, presence of mixed phenotype; Trauma-/MP+), 2 (high trauma, absence of mixed phenotype; Trauma $+/ \mathrm{MP}-$ ), and 3 (high trauma, presence of mixed phenotype; Trauma $+/ \mathrm{MP}+$ ).

\subsection{Analyses}

Two sets of analyses were performed. The first involved the analysis of the repeated assessments of stress and NA collected using ESM and examined the data for group difference with respect to emotional reactivity. Second, we examined the relationship between the follow-up SCL-90 global symptom severity score and emotional reactivity. Due to the multilevel structure of the data (with individuals nested within twin pairs, and for the first two sets of analyses, with the repeated assessments/measurements nested within individuals), multilevel (mixed-effects) linear regression models were used for all analyses (see below for details). The models were fitted using the MIXED command with Stata, version 13 (Statacorp, 2013), and all models were adjusted for age at baseline. Analyses were adjusted for age by adding it as covariate.

\subsubsection{Emotional reactivity}

Following previous work (Lardinois et al., 2011; van Winkel et al., 2015), emotional reactivity to stress was operationalized by estimating the association between stress (either event, activity, or social) and NA, assessed at the same beep. Multilevel models were estimated with stress (continuous), group (factor with 4 levels), and their interaction as independent variables and NA as the dependent variable. Consequently, a significant interaction indicates group differences in emotional (NA) reactivity to stress. Three separate analyses were performed, one for each stressor. All models included random intercepts and slopes (for the stress variable) at the individual and twin pair level, with intercepts and slopes allowed to be correlated. Based on these models, we estimated and report pairwise differences between the groups with respect to the coefficient relating the stressor to the outcome. Due to multiple testing (i.e., three stress types, and five group contrasts; 15 tests), the level of significance was set at 0.003 (Bonferroni correction; 0.05/15).

\subsubsection{Symptom severity at follow-up}

As the ESM data and the data used to form the groups were both assessed at baseline, no inferences can be made on the direction of the effects. Thus, additional analyses using the follow-up measurement were performed. For each participant, a single regression coefficient was estimated that expresses emotional reactivity to stress (one for each stress type). This coefficient was obtained by regressing negative affect on (event, activity, or social) stress using all available beeps within each participant, resulting in one regression coefficient (beta) per person, rather than one coefficient that expresses the average relationship for an entire group of participants (for a more detailed description, see Lataster et al., 2010). Next, associations between emotional reactivity to stress and follow-up SCL-90 global symptom severity were assessed using a multilevel model (with random intercepts at the twin-pair level), adding SCL-90 global symptom severity at baseline as a confounder. These analyses were performed in each group separately. Due to multiple testing (three stress coefficients, four groups), the level of significance was set at 0.004 (Bonferroni correction; 0.05/12). 


\section{Results}

\subsection{Sample}

The total sample consisted of 621 white females between the age of 18 and 61 (mean age: 27.7, SD $=7.9$ years). Of these, 618 participants had available data for the SCL, and 609 completed the childhood trauma questionnaire (data for both questionnaires was available for 606 participants). Participants without completed SCL and trauma questionnaires did not differ in terms of age, education level, anxiety, depression, and psychosis scores from participants with complete datasets. A total number 610 participants participated in the ESM measurement. 31 subjects were excluded because they had $<17$ valid ESM self-reports. Another 15 subjects were excluded because of missing data on NA or stress. This resulted in a dataset of 564 subjects with complete ESM data, and SCL and trauma questionnaires at baseline. Participants without complete ESM data did not differ in terms of age, education levels, depression, and psychosis scores from participants who had complete datasets. Participants without a complete ESM dataset did however have higher SCL-90 anxiety scores (mean 0.27) than subjects with complete datasets (mean $0.12, t=3.52, p<0.001$ ).

483 subjects participated in the follow-up measurement. Subjects lost to follow-up did not differ in terms of age, education level, baseline depression, and baseline psychosis scores compared with responders. Non-participants did however report higher levels of baseline SCL-90 anxiety (mean 0.18) than participants (mean $0.12, t=2.27, p=0.02$ ). An overview of the sample at baseline and follow-up is shown in Table 1.

Reliability for the shortened trauma measure was high (Cronbach's alpha $=0.93$ ). For constructs measured with more than one item (i.e., activity stress, social stress, and negative affect), we estimated the reliability of the mean of the items for detecting systematic changes in the construct over beeps using the method described by Cranfordet al. (2006, eq. 5). We found estimates of $0.52,0.78$, and 0.65 for the three aforementioned constructs, respectively.

\subsection{Stress reactivity}

Results indicated that individuals with a trauma history, who additionally had a mixed phenotype of psychopathology, showed a stronger emotional reaction to activity and social stress than traumatized subjects without a mixed phenotype (Table 2, last column). Nontraumatized individuals with a mixed phenotype showed a stronger emotional reaction to activity and social stress than non-traumatized individuals without a mixed phenotype (Trauma-/MP- vs Trauma-/MP + ; Table 2, first column). In the absence of a mixed phenotype (Trauma-/MP- vs Trauma +/MP-; second column), there was no evidence that having a trauma history altered emotional reactivity to stress. On the other hand, trauma exposure was associated with a heightened reactivity to activity and social stress in the mixed phenotype group (Trauma-/MP + vs Trauma +/MP +; fourth column), although the effect did not reach the Bonferroni adjusted level of significance. By comparing the two most 'extreme' groups (Trauma-/MPvs Trauma + /MP +, third column), the largest differences in emotional reactivity to stress were found, with individuals who were exposed to trauma and who had a mixed phenotype being the most stress reactive. These results were similar for event stress, activity stress, and social stress.

\subsection{Symptom severity at follow-up}

Event stress was associated with global symptom severity at followup, but only in the trauma-exposed mixed phenotype group (B 0.58 , $95 \%$ Confidence Interval $0.23-0.93, p=0.001$ ). No significant associations were found for the other stress types, or in the other three subgroups.
Table 1

Descriptives.

\begin{tabular}{|c|c|c|}
\hline & $\begin{array}{l}\text { T0 }(n=606) \\
\text { Mean (SD) }\end{array}$ & $\begin{array}{l}\text { T4 }(\mathrm{n}=483) \\
\text { Mean (SD) }\end{array}$ \\
\hline Age & $27.7(7.9)$ & j \\
\hline Childhood trauma $^{\mathrm{a}}$ & $1.67(0.58)$ & n.a. \\
\hline $\mathrm{NA}^{\mathrm{b}}$ & $1.34(0.63)$ & n.a. \\
\hline Event stress $^{c}$ & $0.22(0.66)$ & n.a. \\
\hline Activity stress ${ }^{\mathrm{d}}$ & $2.58(1.24)$ & n.a. \\
\hline Social stress ${ }^{\mathrm{e}}$ & $2.11(1.24)$ & n.a. \\
\hline \multirow[t]{2}{*}{ SCL-90 global symptom severity ${ }^{f}$} & $1.39(0.36)$ & $1.34(0.39)$ \\
\hline & $\mathrm{N}(\%)$ & $\mathrm{N}(\%)$ \\
\hline Anxiety (dichotomized) ${ }^{g}$ & $229(38)$ & $150(31)$ \\
\hline Depression (dichotomized) ${ }^{\mathrm{h}}$ & $273(45)$ & $201(42)$ \\
\hline Psychosis (dichotomized) ${ }^{\mathrm{i}}$ & $186(31)$ & $125(26)$ \\
\hline $\begin{array}{l}\text { Childhood trauma (dichotomized by 80th } \\
\text { percentile) }\end{array}$ & $126(21)$ & n.a. \\
\hline \multicolumn{3}{|l|}{ Childhood trauma \& symptom profile } \\
\hline $\begin{array}{l}\text { Trauma-/MF- (no trauma, no or isolated } \\
\text { symptoms) }\end{array}$ & $318(52)$ & $283(59)$ \\
\hline Trauma-/MF + (no trauma, mixed phenotype) & $162(27)$ & $101(21)$ \\
\hline $\begin{array}{l}\text { Trauma }+/ \text { MF- (trauma, no or isolated } \\
\text { symptoms) }\end{array}$ & $56(9)$ & $48(10)$ \\
\hline Trauma + /MF + (trauma, mixed phenotype) & $70(12)$ & $51(11)$ \\
\hline \multicolumn{3}{|l|}{ Education level } \\
\hline Primary & $13(2)$ & $9(2)$ \\
\hline Secondary & 214 (37) & $163(34)$ \\
\hline Tertiary & $356(61)$ & 302 (64) \\
\hline
\end{tabular}

${ }^{\text {a }}$ Childhood trauma measured with a 21 item (scored 1 [never] to 5 [always] questionnaire based on the Childhood Trauma Questionnaire; the most explicit items concerning sexual and physical abuse were omitted. A continuous childhood trauma score was calculated based on the mean of all items (possible range 1-5).

${ }^{\mathrm{b}}$ Average score of six negative affect (NA) items (insecure, down, lonely, anxious, irritated, and guilty) each measured on a 7-point Likert scale, ranging from 1 (not at all) to 7 (very), using the Experience Sampling Method (ESM).

c Appraisal of recent event (1 item), ranging from 0 (neutral) to 3 (very unpleasant), measured using ESM.

${ }^{\mathrm{d}}$ Average score of appraisal of current activity (3 items), all ranging from 1 (not at all) to 7 (very), measured using ESM.

e Average score of appraisal of current company (2 items), both ranging from 1 (not at all) to 7 (very), measured using ESM.

${ }^{\mathrm{f}}$ Mean of all 90 items of the Symptom CheckList (SCL-90).

${ }^{\mathrm{g}}$ Presence of at least one of 10 anxiety items, scoring 3 or higher (somewhat, quite a bit, very much so).

${ }^{\mathrm{h}}$ Presence of at least one of 13 depression items, scoring 3 or higher.

${ }^{\mathrm{i}}$ Presence of at least one of 16 psychosis items, scoring 3 or higher.

${ }^{\mathrm{j}}$ Total follow-up time (T0-T4) was \pm 430 days.

\section{Discussion}

Individuals who show a mixed phenotype of psychopathology have an increased level of daily life emotional stress reactivity, regardless of type of daily stressor. At the Bonferroni adjusted level of significance, the cross-sectional analyses indicated no contrasts in stress reactivity due to trauma exposure. However, some unadjusted significant contrasts were found due to trauma exposure in the mixed phenotype group. In addition, in subjects with a trauma history and a mixed phenotype, event-related stress reactivity at baseline predicted more severe symptoms at follow-up.

These findings indicate that when assessed cross-sectionally, the presence of a mixed phenotype may be linked to increased emotional stress responses to daily life stressors. However, when assessing individuals longitudinally, the association between stress reactivity and symptom development was only relevant in a subgroup stratified by both trauma exposure and symptom phenotype (with regard to eventstress only). This may suggest that increased stress-reactivity is a state effect of having co-occurring psychiatric symptoms in those without a trauma history, whereas in victims of childhood trauma, increased emotional stress-reactivity may actually lie on the etiological pathway to a mixed phenotype, in line with our hypotheses. The (non-significant 
Table 2

Emotional reactivity to stress.

\begin{tabular}{|c|c|c|c|c|c|}
\hline Group & $\begin{array}{l}\text { Trauma-/MP + }(\mathrm{n}=162) \\
\text { vs }\end{array}$ & $\begin{array}{l}\text { Trauma +/MP- }(\mathrm{n}=56) \\
\text { vs }\end{array}$ & $\begin{array}{l}\text { Trauma + /MP + }(n=70) \\
\text { vs }\end{array}$ & $\begin{array}{l}\text { Trauma + /MP + (n = 70) } \\
\text { vs }\end{array}$ & $\begin{array}{l}\text { Trauma }+/ M P+(\mathrm{n}=70) \\
\text { vs }\end{array}$ \\
\hline comparisor & Trauma-/MP- $(\mathrm{n}=318)$ & Trauma-/MP- $(\mathrm{n}=318)$ & Trauma-/MP- $(\mathrm{n}=318)$ & Trauma-/MP + $(\mathrm{n}=162)$ & Trauma +/MP- $(\mathrm{n}=56)$ \\
\hline $\begin{array}{l}\text { B coefficients } \\
\text { indicate }\end{array}$ & $\begin{array}{l}\text { Association of mixed } \\
\text { phenotype with stress } \\
\text { sensitivity in non- } \\
\text { traumatized individuals }\end{array}$ & $\begin{array}{l}\text { Association of trauma with } \\
\text { stress sensitivity in } \\
\text { individuals without mixed } \\
\text { phenotype }\end{array}$ & $\begin{array}{l}\text { Association of trauma and } \\
\text { mixed phenotype with stress } \\
\text { sensitivity (vs absence of } \\
\text { both) }\end{array}$ & $\begin{array}{l}\text { Association of trauma with } \\
\text { stress sensitivity in } \\
\text { individuals with mixed } \\
\text { phenotype }\end{array}$ & $\begin{array}{l}\text { Association of mixed } \\
\text { phenotype with stress } \\
\text { sensitivity in traumatized } \\
\text { individuals }\end{array}$ \\
\hline & $\mathrm{B}^{\mathrm{a}}(\mathrm{CI}), \mathrm{p}$ & $\mathrm{B}^{\mathrm{a}}(\mathrm{CI}), \mathrm{p}$ & $\mathrm{B}^{\mathrm{a}}(\mathrm{CI}), \mathrm{p}$ & $\mathrm{B}^{\mathrm{a}}(\mathrm{CI}), \mathrm{p}$ & $\mathrm{B}^{\mathrm{a}}(\mathrm{CI}), \mathrm{p}$ \\
\hline Event stress & $\begin{array}{l}0.07(0.02-0.13) \\
0.006\end{array}$ & $\begin{array}{l}0.06(-0.14-0.14) \\
0.112\end{array}$ & $\begin{array}{l}0.11^{*}(0.04-0.18) \\
0.002\end{array}$ & $\begin{array}{l}0.04(-0.04-0.11) \\
0.338\end{array}$ & $\begin{array}{l}0.05(-0.04-0.14) \\
0.310\end{array}$ \\
\hline Activity stress & $\begin{array}{l}0.05^{*}(0.03-0.08) \\
<0.001\end{array}$ & $\begin{array}{l}0.01(-0.02-0.05) \\
0.551\end{array}$ & $\begin{array}{l}0.09^{*}(0.06-0.13) \\
<0.001\end{array}$ & $\begin{array}{l}0.04(0.01-0.07) \\
0.022\end{array}$ & $\begin{array}{l}0.08^{*}(0.04-0.13) \\
<0.001\end{array}$ \\
\hline Social stress & $\begin{array}{l}0.07^{*}(0.04-0.10) \\
<0.001\end{array}$ & $\begin{array}{l}0.03(-0.01-0.07) \\
0.146\end{array}$ & $\begin{array}{l}0.12^{*}(0.08-0.16) \\
<0.001\end{array}$ & $\begin{array}{l}0.05(0.01-0.09) \\
0.019\end{array}$ & $\begin{array}{l}0.09^{*}(0.03-0.14) \\
0.001\end{array}$ \\
\hline
\end{tabular}

CI; 95\% confidence interval.

$* \mathrm{p}<0.003$ (adjusted level of significance after Bonferroni correction [0.05/15]), adjusted for age.

${ }^{\text {a }}$ Interaction coefficient of group $\mathrm{x}$ stress, in association with NA.

at $\mathrm{p}<0.002$ ) differences in the baseline comparison between $\mathrm{CT}+/ \mathrm{MP}$ + and CT-/MP + may be in line with this interpretation. A further step is to uncover why this subgroup shows this developmental pattern, which may be found in the field of epigenetics (Mehta et al., 2013; Perroud et al., 2014), or through studies investigating for example early coping strategies (Harris et al., 2015) or peer/parent relationships (Lowell et al., 2014). Interestingly, individuals with a history of trauma and a mixed phenotype perceived certain events more stressful then individuals with a history of trauma but without a mixed phenotype. Different kinds of resilience mechanisms might be at play here. For example, previous studies have found that a less negative bias towards emotional cues is protective of later psychopathology. One possible underlying explanation could be that a cognitive bias impairs how people see the world, which in turn influences interpersonal functioning. A less impaired cognitive bias might allow the maltreated individual to develop good relationships with others, which is a protective factor in itself (e.g. Suzuki et al., 2015; Collishaw et al., 2007; Surguladze et al., 2004; for a review see Olff et al., 2009). More prospective research looking at possible resilience factors is warranted.

Other than providing evidence for an underlying stress-related mechanism, these findings may inform the search for additional treatment options in exposed individuals. Targeted treatment with a focus on trauma (De Bont et al., 2013) or stress-reducing techniques (Williams et al., 2014) may be beneficial for patients who were exposed to trauma, and in particular those who also have a mixed phenotype. The clinical utility of looking into this group more closely is also stressed by previous research providing evidence that patients with a history of trauma and a mixed phenotype (i.e. mood disorder, anxiety disorder, psychotic disorder) report a lower quality of life, more helpseeking behaviour, more substance abuse, higher levels of psychotropic medication and lower general functioning (Van Nierop et al., 2016). However, the current study is based on a general population sample, therefore these hypotheses need to be tested in clinical samples.

Some inconsistencies in the present results need to be addressed. In the cross-sectional comparison of the subgroups, contrasts were found particularly for activity and social stress, whereas event related stress was associated with symptom severity at follow-up. The latter inconsistency could be due to the relatively short follow-up duration (just over a year), and it is possible that symptom development could be picked up in a longer follow-up period in response to activity and social stress reactivity as well. However, event stress may be a more direct measure of the traditional 'daily hassles', as opposed to activity or social stress, which may explain the stronger association with symptom development over time (Kanner et al., 1981). We did find some evidence for event-related stress reactivity in the cross-sectional analyses. The non-significant findings could have been due to a power issue (as activity stress is measured at each beep, whereas event stress is only measured during negative events) or the choice of a relatively strict Bonferroni correction. Conceptual differences between the separate stress measures remain unclear, and the possibility that reactivity to activity, social, or event related stress may rely on different stress mechanisms has so far not been addressed. Furthermore, comparing the Trauma + /MP + mixed phenotype group with the Trauma-/MP- group generates the largest contrast and thus, is most likely to pick up significant findings, whereas contrasts with the other groups (Trauma-/MP + , Trauma +/MP-) may generate significant findings less easily. However, if we assume that the developmental pathway from the exposure to childhood trauma to a mixed phenotype is via a process of increased stress-reactivity, then the group with trauma exposure but no mixed phenotype should not (or to a lesser degree) show increased stress reactivity. Thus, including this comparison is very important in order to examine whether increased stress reactivity is a general consequence of exposure to childhood trauma, irrespective of the psychopathology that victims may or may not develop, or may be a potentially causal mechanism that is only present in those with a mixed phenotype.

The current findings should be interpreted in light of some strengths and weaknesses. No data was available on cannabis use in this sample, so any influence that cannabis may have had on the relationship between childhood trauma, stress reactivity, and phenotype could not be controlled for. However, when adjusting for cannabis use in previous studies, results were mostly not significantly influenced (van Nierop et al., 2014, 2015a; van Dam et al., 2014). The most explicit childhood trauma items on sexual and physical abuse were omitted in this study. This could have resulted in an underestimation of the effects of trauma, as it is possible that individuals exposed to sexual trauma may have been placed in the non-traumatized group. Earlier studies have indicated that different types of trauma do tend to co-occur within individuals (Bellis et al., 2014) however, therefore it is unlikely that this omission would have impacted the results. Our long-term follow-up contributed to attrition of mostly anxious participants, which may have influenced our results. Furthermore, childhood trauma was assessed retrospectively at baseline. Nevertheless, studies indicate that retrospective reports of childhood trauma are reliable, even in individuals with a mental illness (Fisher et al., 2011). Psychopathology was assessed via a symptom checklist rather than via a clinical diagnosis by a trained professional. However, the psychometric properties of this measure are generally high $(r=0.75-0.87$; test-retest $r=0.69-0.92)$ (Franke, 2000). All participants were female, thus further studies are necessary to investigate whether a similar mechanism is also relevant in males, particularly in light of earlier findings of gender differences in the link between trauma and psychopathology (Fisher et al., 2009). Generalizability may have been limited by using a twin sample. Twins 
share their genetic mark-up and may thus represent a special sub-group that is to some extent different from the general population. This was taken under consideration, however, by using multilevel analyses and thereby taking twin-clusters into account (individuals nested within twin pairs). Interestingly, not all participants with a history of childhood trauma were found to have mixed symptoms. It may thus be that these individuals are psychologically, socially, or biologically resilient. It would be interesting to test this in a future study. Important strengths of this study are the sample size, and the inclusion of follow-up data, making it possible to test the direction of the effect (stress reactivity leading to psychopathology). ESM emotional stress reactivity was measured using several types of stress (activity related, event related, and social stress).

In conclusion, this study has found evidence that may link a heightened emotional reactivity to daily stressors to a mixed phenotype of psychopathology. Furthermore, heightened reactivity to stress, in particular event and social stress, in individuals with trauma may be a predictor of later psychopathological co-morbidity. Future studies are needed to confirm these results, as well as the impact of different kinds of stressors in the development of psychopathology and the underlying biological substrates of this mechanism.

\section{Funding}

This study was funded by an NWO grant to Jim van Os (project 90457-116). This work was supported by an ERC consolidator grant (ERC2012-StG, project 309767 - INTERACT) to Inez Myin-Germeys and a FWO Senior Clinical Investigator grant to Ruud van Winkel.

\section{References}

Ahmed, S., Sami, A., Xiang, J., 2015. HER2-directed therapy: current treatment options for HER2-positive breast cancer. Breast Cancer 22 (2), 101-116.

Bellis, M.A., Hughes, K., Leckenby, N., Perkins, C., Lowey, H., 2014. National household survey of adverse childhood experiences and their relationship with resilience to health-harming behaviors in England. BMC Med. 12, 72.

Bernstein, D.P., Fink, L., Handelsman, L., Foote, J., Lovejoy, M., Wenzel, K., Sapareto, E., Ruggiero, J., 1994. Initial reliability and validity of a new retrospective measure of child abuse and neglect. Am. J. Psychiatry 151 (8), 1132-1136.

Bernstein, D.P., Ahluvalia, T., Pogge, D., Handelsman, L., 1997. Validity of the childhood trauma questionnaire in an adolescent psychiatric population. J. Am. Acad. Child Adolesc. Psychiatry 36 (3), 340-348.

Bria, E., De Manzoni, G., Beghelli, S., Tomezzoli, A., Barbi, S., Di Gregorio, C., Scardoni, M., Amato, E., Frizziero, M., Sperduti, I., Corbo, V., Brunelli, M., Bersani, S., Tortora, G., Scarpa, A., 2013. A clinical-biological risk stratification model for resected gastric cancer: prognostic impact of Her2, Fhit, and APC expression status. Ann. Oncol. 24 (3), 693-701.

Collip, D., Myin-Germeys, I., van Os, J., 2008. Does the concept of 'sensitization' provide a plausible mechanism for the putative link between the environment and schizophrenia? Schizophr. Bull. 34, 220-225.

Collishaw, S., Pickles, A., Messer, J., Rutter, M., Shearer, C., Maughan, B., 2007. Resilience to adult psychopathology following childhood maltreatment: evidence from a community sample. Child Abus. Negl. 31 (3), 211-229.

Cranford, J.A., Shrout, P.E., Iida, M., Rafaeli, E., Yip, T., Bolger, N., 2006. A procedure for evaluating sensitivity to within-person change: can mood measures in diary studies detect change reliably? Personal. Social Psychol. Bull. 32 (7), 917-929.

Csikszentmihalyi, M., Larson, R., 1987. Validity and reliability of the experience-sampling method. J. Nerv. Ment. Dis. 175, 526-536.

De Bont, P.A., van den Berg, D.P., van der Vleugel, B.M., de Roos, C., Mulder, C.L., Becker, E.S., de Jongh, A., van der Gaag, M., van Minnen, A., 2013. A multi-site single blind clinical study to compare the effects of prolonged exposure, eye movement desensitization and reprocessing and waiting list on patients with a current diagnosis of psychosis and co morbid post traumatic stress disorder: study protocol for the randomized controlled trial Treating Trauma in Psychosis. Trials 14, 151.

Delespaul, P., 1995. Assessing Schizophrenia In Daily Life: The Experience Sampling Method. University of Limburg, Maastricht.

Derogatis, L.R., Rickels, K., Rock, A.F., 1976. The SCL-90 and the MMPI: a step in the validation of a new self-report scale. Brit. J. Psychiatry 128, 280-289.

Derom, C., Thiery, E., Peeters, H., Vlietinck, R., Defoort, P., Frijns, J.P., 2013. The Eas Flanders Prospective Twin Survey (EFPTS): an actual perception. Twin Res. Hum. Genet. 16 (1), 58-63.

DeVries, M.W., 1992. The Experience of Psychopathology: Investigating Mental Disorders in Their Natural Settings. Cambridge University Press, Cambridge.

Fisher, H., Morgan, C., Dazzan, P., Craig, T., Thomas, K., Morgan, K., Hutchinson, G., Jones, P.B., Doody, G.A., Pariante, C., McGuffin, P., Murray, R.M., Leff, J., Fearon, P., 2009. Gender differences in the association between childhood abuse and psychosis.
Brit. J. Psychiatry 194 (4), 319-325

Fisher, H.L., Craig, T.K., Fearon, P., Morgan, K., Dazzan, P., Lappin, J., Hutchinson, G., Doody, G.A., Jones, P.B., McGuffin, P., Murray, R.M., Leff, J., Morgan, C., 2011.

Reliability and comparability of psychosis patients' retrospective reports of childhood abuse. Schizophr. Bull. 37 (3), 546-553.

Franke, G.H., 2000. Die Symptom-Checkliste von Derogatis (SCL-90-R) - Deutsche Version Manual. Beltz Test, Gottingen.

Glaser, J.P., van Os, J., Portegijs, P.J., Myin-Germeys, I., 2006. Childhood trauma and emotional reactivity to daily life stress in adult frequent attenders of general practitioners. J. Psychosom. Res. 61 (2), 229-236.

Harris, L.S., Block, S.D., Ogle, C.M., Goodman, G.S., Augusti, E.M., Larson, R.P., Culver, M.A., Pineda, A.R., Timmer, S.G., Urquiza, A., 2015. Coping style and memory specificity in adolescents and adults with histories of child sexual abuse. Memory 8, 1078-1090.

Heins, M., Simons, C., Lataster, T., Pfeifer, S., Versmissen, D., Lardinois, M., Marcelis, M., Delespaul, P., Krabbendam, L., van Os, J., Myin-Germeys, I., 2011. Childhood trauma and psychosis: a case-control and case-sibling comparison across different levels of genetic liability. Psychopathol., Type Trauma. Am. J. Psychiatry 168 (12), 1286-1294.

Hektner, D., Schmidt, J.A., Csikszentmihalyi, M., 2007. Experience Sampling Method: Measuring the Quality of Everyfay Life. Sage Publications, London.

Kapur, S., Phillips, A.G., Insel, T.R., 2012. Why has it taken so long for biological psychiatry to develop clinical tests and what to do about it? Mol. Psychiatry 17, 1174-1179.

Lardinois, M., Lataster, T., Mengelers, R., Van Os, J., Myin-Germeys, I., 2011. Childhood trauma and increased stress sensitivity in psychosis. Acta Psychiatry Scand. 123 (1), 28-35.

Lataster, T., Collip, D., Lardinois, M., van Os, J., Myin-Germeys, I., 2010. Evidence for a familial correlation between increased reactivity to stress and positive psychotic symptoms. Acta Psychiatry Scand. 122 (5), 395-404.

Lindert, J., von Ehrenstein, O.S., Grashow, R., Gal, G., Braehler, E., Weisskopf, M.G., 2014. Sexual and physical abuse in childhood is associated with depression and anxiety over the life course: systematic review and meta-analysis. Int. J. Public Health 59 (2), 359-372.

Lowell, A., Renk, K., Adgate, A.H., 2014. The role of attachment in the relationship between child maltreatment and later emotional and behavioral functioning. Child Abus. Negl. 38 (9), 1436-1449.

McGowan, P.O., Sasaki, A., D'Alessio, A.C., Dymov, S., Labonte, B., Szyf, M., Turecki, G. Meaney, M.J., 2009. Epigenetic regulation of the glucocorticoid receptor in human brain associates with childhood abuse. Nat. Neurosci. 12 (3), 342-348.

Mehta, D., Klengel, T., Conneely, K.N., Smith, A.K., Altmann, A., Pace, T.W., Ref-Haffner, M., Loeschner, A., Gonik, M., Mercer, K.B., Bradley, B., Müller-Myhsok, B., Ressler, K.J., Binder, E.B., 2013. Childhood maltreatment is associated with distinct genomic and epigenetic profiles in posttraumatic stress disorder. Proc. Natl. Acad. Sci. USA 110 (20), 8302-8307.

Myin-Germeys, I., van Os, J., Schwartz, J.E., Stone, A.A., Delespaul, P.A., 2001. Emotional reactivity to daily life stress in psychosis. Arch. Gen. Psychiatry 58, 1137-1144.

Myin-Germeys, I., van Os, J., 2007. Stress-reactivity in psychosis: evidence for an affective pathway to psychosis. Clin. Psychol. Rev. 27, 409-424.

Myin-Germeys, I., Oorschot, M., Collip, D., Lataster, J., Delespaul, P., van Os, J., 2009. Experience sampling research in psychopathology: opening the black box of daily life. Psychol. Med. 39, 1533-1547.

Olff, M., Langelan, W., Draijer, N., Gersons, B.P., 2009. Gender differences in posttraumatic stress disorder. Psychol. Bull. 1333 (2), 183-204.

Perroud, N., Dayer, A., Piguet, C., et al., 2014. Childhood maltreatment and methylation of the glucocorticoid receptor gene NR3C1 in bipolar disorder. Br. J. Psychiatry 204, 30-35.

Petrakos, I., Kontzoglou, K., Nikolopoulos, T.P., Papadopoulos, O., Kostakis, A., 2012. Glottic and supraglottic laryngeal cancer: epidemiology, treatment patterns and survival in 164 patients. J. BUON 17 (4), 700-705.

Pohl, J., Olmstead, M.C., Wynne-Edwards, K.E., Harkness, K., Menard, J.L., 2007. Repeated exposure to stress across the childhood-adolescent period alters rats' anxiety- and depression-like behaviors in adulthood: the importance of stressor type and gender. Behav. Neurosci. 121 (3), 462-474.

Statacorp, 2013. Stata Statistical Software: Release 13. StataCorp LP, College Station, TX.

Surguladze, S.A., Young, A.W., Senior, C., Brebion, G., Travis, M.J., Phillips, M.L., 2004 Recognition accuracy and response bias to happy and sad facial expressions in patients with major depression. Neuropsychology 18 (2), 2012-2018.

Suzuki, A., Poon, L., Veena, K., Cleare, A.J., 2015. Fear biases in emotional face processing following childhood trauma as a marker of resilience and vulnerability to depression. Child Maltreat. 20 (4), 240-250.

Teicher, M.H., Samson, J.A., 2013. Childhood maltreatment and psychopathology: a case for ecophenotypic variants as clinically and neurobiologically distinct subtypes. Am. J. Psychiatry 170 (10), 1114-1133.

van Dam, D.S., van Nierop, M., Viechtbauer, W., Velthorst, E., van Winkel, R., Bruggeman, R., Cahn, W., de Haan, L., Kahn, R., Meijer, C.J., Myin-Germeys, I., van Os, J., Wiersma, D., 2014. Childhood abuse and neglect in relation to the presence and persistence of psychotic and depressive symptomatology. Psychol. Med. 45 (7), 1363-1377.

van Nierop, M., Lataster, T., Smeets, F., Gunther, N., van Zelst, C., de Graaf, R., ten Have, M., van Dorsselaer, S., Bak, M., Myin-Germeys, I., Viechtbauer, W., van Os, J., van Winkel, R., 2014. Psychopathological mechanisms linking childhood traumatic experiences to risk of psychotic symptoms. Analysis of a large, representative population-based sample. Schizophr. Bull. 40 (2), S123-S130.

van Nierop, M., Viechtbauer, W., Gunther, N., van Zelst, C., de Graaf, R., ten Have, M., van Dorsselaer, S., Bak, M., GROUP, van Winkel, R., 2015a. Childhood trauma is 
associated with a specific admixture of affective, anxiety, and psychosis symptoms cutting across traditional diagnostic boundaries. Psychol. Med. 45 (6), 1277-1288.

van Nierop, M., Bak, M., de Graaf, R., ten Have, M., van Dorsselaer, S., GROUP, van

Winkel, R., 2015b. The functional and clinical relevance of childhood trauma-related admixture of affectie, anxious, and psychosis symptoms. Acta Psychiatry Scand. http://dx.doi.org/10.1111/acps.12437.

van Winkel, R., Stefanis, N.C., Myin-Germeys, I., 2008. Psychosocial stress and psychosis. A review of the neurobiological mechanisms and the evidence for gene-stress interaction. Schizophr. Bull. 34 (6), 1095-1105.

van Winkel, R., 2015. Aetiological stratification as a conceptual framework for gene-byenvironment interaction research in psychiatry. Epidemiol. Psychiatrry Sci. 24 (1), 6-11.

Varese, F., Smeets, F., Drukker, M., Lieverse, R., Lataster, T., Viechtbauer, W., Read, J., van Os, J., Bentall, R.P., 2012. Childhood adversities increase the risk of psychosis: a meta-analysis of patient-control, prospective- and cross-sectional cohort studies. Schizophr. Bull. 38 (4), 661-671.

Weekes, N.Y., Lewis, R.S., Goto, S.G., Garrison-Jakel, J., Patel, F., Lupien, S., 2008. The effect of an environmental stressor on gender differences on the awakening cortisol response. Psychoneuroendocrino 33 (6), 766-772.

Wichers, M., Schrijvers, D., Geschwind, N., Jacobs, N., Myin-Germeys, I., Thiery, E.,
Derom, C., Sabbe, B., Peeters, F., Delespaul, P., van Os, J., 2009. Mechanisms of geneenvironment interactions in depression: evidence that genes potentiate multiple sources of adversity. Psychol. Med. 39, 1077-1086.

Wigman, J.T.W., van Nierop, M., Vollebergh, W., Lieb, R., Beesdo-Baum, K., Wittchen, H.U., Van Os, J., 2012. Evidence that psychotic symptoms are prevalent in disorders of anxiety and depression, impacting on illness onset, risk, and severity - implications for diagnosis and ultra-high risk research. Schizophr. Bull. 38 (2), 247-257.

Wigman, J.T.W., Collip, D., Wichers, M., Delespaul, P., Derom, C., Thiery, E., Vollebergh, W.A., Lataster, T., Jacobs, N., Myin-Germeys, I., van Os, J., 2013. Altered transfer of momentary mental states (ATOMS) as the basic unit of psychosis liability in interaction with environment and emotions. PLoS One 8 (2), e54653.

Williams, J.M., Crane, C., Barnhofer, T., Brennan, K., Duggan, D.S., Fennell, M.J.V., Hackmann, A., Krusche, A., Muse, K., von Rohr, I.R., Dhruvi, S., Crane, R.S., Eames, C., Jones, M., Radford, S., Silverton, S., Sun, Y., Weatherley-Jones, E., Whitaker, C.J., Russell, D., Russell, I.T., 2014. Mindfulness-based cognitive therapy for preventing relapse in recurrent depression: a randomized dismantling trial. J. Consult. Clin. Psych. 82 (2), 275-286.

Kanner, A.D., Coyne, J.C., Schaefer, C., Lazarus, R.S., 1981. Comparison of two modes of stress measurement: daily hassles and uplifts versus major life events. J. Behav. Med. 4 (1), 1-39. 